Version définitive du manuscrit publié dans / Final version of the manuscript published in : European Journal Plant Pathology, 2011, vol.131, pp 431-440, DOI: 10.1007/s10658-0119820-4

\title{
The reproductive potential of root-knot nematodes Meloidogyne incognita is affected by selection for virulence against major resistance genes from tomato and pepper
}

Caroline Djian-Caporalino $^{\mathrm{a}, *} \cdot$ Sergio Molinari $^{\mathrm{b}} \cdot$ Alain Palloix $^{\mathrm{c}} \cdot$ Aurelio Ciancio $^{\mathrm{b}} \cdot$ Ariane Fazari $^{\mathrm{a}} \cdot$ Nathalie Marteu $^{\mathrm{a}} \cdot$ Nicolas Ris $^{\mathrm{d}} \cdot$ Philippe Castagnone-Sereno $^{\mathrm{a}}$

${ }^{a}$ INRA PACA, UMR1301 INRA/UNSA/CNRS, Interactions Biotiques et Santé Végétale, BP167, F-06903 Sophia Antipolis, France

${ }^{\mathrm{b}} \mathrm{CNR}$, Istituto per la Protezione delle Piante, I-70126 Bari, Italy

'INRA PACA, UR1052, Génétique et Amélioration des Fruits et Légumes, F-84143 Montfavet, France

${ }^{\mathrm{d} I N R A}$ PACA, UE1254, Lutte Biologique, BP167, F-06903 Sophia Antipolis, France

*Author for correspondence. E-mail: Caroline.Caporalino@sophia.inra.fr 


\begin{abstract}
Root-knot nematodes (RKNs, Meloidogyne spp.) are major plant pathogens of vegetables in most production areas, including the Solanaceous crops tomato and pepper. Due to the banning of chemical nematicides, current control strategies are mainly based on the deployment of resistance genes (R-genes), i.e., $M i(\mathrm{~s})$ in tomato, $M e(\mathrm{~s})$ in pepper. These genes are effective against a wide range of RKN species, including $M$. arenaria, $M$. incognita and $M$. javanica, the most common species in temperate and tropical areas. However, the recent emergence of virulent populations able to overcome the resistance conferred by some of these R-genes may constitute a severe limitation to their use in the field. Research has been conducted to evaluate the durability of the $M i(s)$ and $M e(s)$ R-genes, by comparing the reproduction of several laboratory-selected and wild virulent $M$. incognita isolates on both susceptible and resistant tomatoes and peppers. We first showed that the Me1 R-gene in pepper behaves as a robust R-gene controlling avirulent and virulent $\mathrm{Me} 3$ or $\mathrm{Mi}-1$ isolates. We also confirm that virulence is highly specific to a determined R-gene on which selection has occurred, thus allowing the alternance of R-genes in the rotation as an effective mean to improve soil health. Another significant experimental result is the observation that a reproductive fitness cost is associated to nematode virulence. The adaptative significance of trade-offs between selected characters and fitness-related traits suggests that, although the resistance can be broken, it might prove durable in some conditions if the virulent nematodes are counterselected in susceptible plants, which has important consequences for the management of plant resistance in the field.
\end{abstract}

\title{
Key words:
}

Meloidogyne spp. Solanaceae. Me and Mi resistance genes . Reproduction potential . Virulence specificity . Fitness cost of virulence . 


\section{Introduction}

Root-knot nematodes (RKNs), Meloidogyne spp., are extremely polyphagous plant parasites, responsible for estimated losses of more than 80 billions Euros/year (Blok et al. 2008). These yield losses are a problem throughout the EU and are exacerbated by the sophisticated and intensive character of EU agriculture. In addition, new regulations have withdrawn the use of most chemical nematicides since 2006, and nematode problems have been increasing in horticultural crops consequently. In this context, cultivation of grafted vegetables is expanding in Europe, and has been adopted as a nonchemical alternative to methyl bromide in several countries (Methyl Bromide Technical Options Committee 2006). Because of this situation, breeding programs for the selection of resistant cultivars (cvs) and/or rootstocks have recently become a major challenge for breeders. However, the diversity of Meloidogyne species and isolates infecting vegetables in most major production areas worlwide is a threat to the use of single major resistance genes (R-genes) (Castagnone-Sereno 2002). Since resistance sources against these nematodes are rare, management of the R-genes currently available is of crucial importance to preserve their durability.

In Solanaceous species (e.g., tomato, pepper), several R-genes have been identified, that control the three main RKN species, i.e., M. arenaria, M. incognita and M. javanica (Williamson and Kumar 2006), and are currently used in breeding programs. However, the diversity and availability of such R-genes is limited. In tomato, all the modern fresh-market and processing resistant cvs carry the single dominant gene Mi-1, introgressed from a single interspecific hybrid (Williamson and Roberts 2009). For more than 60 years, this gene has been the only source of resistance to RKNs in all the available tomato cvs worlwide, and may be considered as a very stable R-gene in terms of durability. However, although this gene has been an excellent example of the use of host resistance to effectively reduce the need for pesticide application (Sorribas et al. 2005), the lack of diversity in the resistance sources exploited explains in part the emergence and spread of virulent nematode populations able to overcome it (Castagnone-Sereno 2002). Indeed, natural virulent isolates have been reported in many areas of the world where tomato is a major crop, and this trend has been increasing recently (e.g., Tzortzakakis et al. 2005, 2008; Verdejo-Lucas et al. 2009; Devran and Sogut 2010), which could significantly reduce the duration of the commercial exploitation of the current R-gene. Moreover, the artificial selection of virulent lineages from progenies of avirulent Meloidogyne isolates was demonstrated by repetitive inoculations onto Mi-1resistant tomato genotypes under laboratory and greenhouses conditions (Jarquin-Barberena et al. 1991; Castagnone-Sereno et al. 1994b; Meher et al. 2009).

In pepper, resistance to RKNs is controlled by several linked dominant genes, i.e., the Me genes. Three of them (Me1, Me3, Me7), in inbred lines originating from three genetically distant accessions, are effective against a wide range of RKN species (Hendy et al. 1985; Djian-Caporalino et al. 1999; 2001; 2007). However, in laboratory experiments, the selection of virulent variants toward the Me3 gene was achieved by using drastic selection pressure of avirulent $\mathrm{M}$. incognita populations, while the Me1 gene could not be overcome (CastagnoneSereno et al. 1996; 2001). Although obtained in experimental assays, these results suggested that these R-genes may differ in their durability if repeatedly used under field conditions. 
Few data are available in litterature about the reproductive potential of RKNs virulent against R-genes from Solanaceous vegetables, and reports appear somehow conflicting. Experimental evaluation of the fecundity (i.e., production of egg-masses by mature females) of Meloidogyne field populations virulent against the tomato Mi R-gene did not show any significant differences when the nematodes were inoculated onto susceptible vs. resistant plants (Castagnone-Sereno et al. 1994a; Tzortzakakis et al. 1998). Conversely, another study indicated that Mi-virulent nematodes produced fewer eggs per gram of root on resistant tomatoes compared to susceptible ones (Huang et al. 2004). More recently, a lower reproduction of $\mathrm{M}$. incognita was found associated to virulence against $\mathrm{Mi}-1$ when inoculated onto susceptible tomatoes, using a combination of female fertility, fecundity and egg hatching as a global measure of reproduction (Castagnone-Sereno et al. 2007). In addition, as far as we know, no such information is currently available concerning RKN populations exhibiting virulence against the pepper Me R-genes.

The first objective of the present study was to compare the reproduction of several laboratoryselected and wild virulent $\mathrm{M}$. incognita isolates on both susceptible and resistant tomatoes and peppers. For that purpose, we evaluated the ability of the juveniles to mature into adult females and produce eggs. A further objective was to determine whether reproductive fitness costs may be associated with the ability of the nematodes to overcome the tomato and pepper R-genes, by comparing the reproductive parameters of $M$. incognita isogenic lines that differ only for their virulence on a set of resistant and susceptible host genotypes. Such costs could have important consequences for the management of plant resistance in the field.

\section{Materials and methods}

\section{Plant material}

Tomato (Solanum lycopersicon) cvs Saint Pierre and Marmande, susceptible to $M$. arenaria, M. incognita and M. javanica, and cvs Piersol and VFN8, homozygous for the Mi-1 gene and resistant to the same three Meloidogyne species, were used in the experiments.

Pepper (Capsicum annuum) genotypes used in this work were inbred lines with differential resistances to the three RKN species. Doux Long des Landes (DLL) is a susceptible cv; Yolo Wonder (YW) exhibits a partial (i.e., a low level of quantitative) resistance to some RKN populations; the two resistant haplo-diploid lines, HD149 and HD330, produced through in vitro androgenesis (Dumas de Vaulx et al. 1981) are homozygous for the Me3 and Me1 genes, respectively (Hendy et al. 1985); the inbred pepper line Criollo de Morelos 334 (CM334) was selfed in insect-proof cages to eliminate outcrossing and was assumed to be homozygous for the major dominant resistance gene previously named Me7 (Djian-Caporalino et al. 2007).

\section{Nematode isolates}

Twelve $M$. incognita isolates were used. Their geographical origin and (a)virulence against the tomato $\mathrm{Mi}-1$ or pepper $\mathrm{Me} 3$ and $\mathrm{Me} 7 \mathrm{R}$-genes are reported in Table 1. Prior to multiplication, each isolate was specifically identified according to its isoesterase electrophoretic pattern (Dalmasso and Bergé, 1978) and/or by SCAR-PCR (Zijlstra et al. 2000). All nematode isolates were maintained in the greenhouse. Hatched second-stage 
juveniles (J2s) were obtained in a mist chamber from previously inoculated roots. Nematodes were collected in water every 48 hours and used immediately.

The avirulent nematode isolates used in this study were collected originally from heavily infested fields or greenhouses, in areas where resistant tomatoes and peppers have not been cultivated.

From the Morelos $M$. incognita avirulent isolate, virulent lines were laboratoryselected and reared by successive re-inoculation on the Mi-1-tomato cv Piersol, or the Me3pepper HD149 line, or the Me7-pepper CM334 line for more than 25 generations according to the procedure of Jarquin-Barberena et al. (1991). The virulent isolates (A, B, C) from Hungary have been naturally selected on resistant peppers carrying $M e 3$ in greenhouses. The Mi-1 virulent SM1 and SM2V isolates have been selected under controlled greenhouse conditions from the avirulent wild-type isolates avir Mifiell and avir MifieldV, respectively, by repeated inoculations on resistant tomato for about 40 generations.

\section{Experimental procedures and infestation parameters}

Tomato and pepper seedlings of cvs susceptible and resistant to RKNs were grown individually in $100 \mathrm{ml}$ pots containing steam-sterilized sandy soil covered by a $1 \mathrm{~cm}$ layer of loam. Six to twenty replicates were performed for each cultivar and each nematode isolate tested. Experiments were conducted in climatic chambers maintained at $24^{\circ} \mathrm{C}\left( \pm 2^{\circ} \mathrm{C}\right)$ with a 12-h light cycle and a relative humidity of $60-70 \%$. For each nematode isolate, six to sevenweek-old plants (4-6 true leaves) were inoculated with a water suspension of 300 to $500 \mathrm{~J} 2 \mathrm{~s}$.

Six to seven weeks after inoculation (i.e., a duration that allowed completion of the nematode life cycle), plants were harvested, carefully washed individually with tap-water, and stained for 10 minutes in an aqueous solution of $0.45 \%$ eosin yellow, to specifically stain egg masses (EMs) in red. The roots were then rinsed and examined under a magnifying glass and the number of EMs counted for each plant.

For each plant, up to 10 EMs were removed at random from the root system and the eggs were separated from the gelatinous matrix in $0.9 \% \mathrm{NaOCl}$, mounted in water between a glass side and a cover slip and counted under a stereomicroscope. Three repeats per plant were achieved.

Three parameters of infestation were calculated:

- the Infestation Frequency (IF) was calculated according to the following ratio: IF = number of EMs/number of J2s inoculated. IF theoretically ranged from 0 (no reproduction at all) to 1 (each juvenile inoculated could develop into a gravid female and generate one EM);

- the Female Fertility (FF) was evaluated as the average number of eggs per EM (i.e., the number of eggs produced by each female);

- the Reproduction Potential (RP) of the nematode population defined as the number of eggs /number of J2s inoculated, following formula: RP $=\mathrm{IF} \times \mathrm{FF}$.

The virulence costs $\left(\mathrm{C}_{\mathrm{h}}\right)$ of the laboratory-selected virulent lines on the susceptible host were estimated as follows: $\mathrm{C}_{\mathrm{h}}(\%)=1$ - RP(virulent line)/RP(avirulent line) (CastagnoneSereno et al. 2007). 


\section{Statistical analysis}

In order to evidence a possible cost of virulence, the Reproduction Potentials (RP) on the susceptible tomato of a restricted set of genotypes (avir F, avir Mifield1, avir MifieldV, vir SM1, vir SM2V, vir Me3, vir Me7) were compared. A Kruskal-Wallis test was firstly carried out. Wilcoxon-Mann-Whithney unilateral tests were then used for post hoc comparisons in order to check if, for a similar genetic background, avirulent strains have higher RP than virulent ones. This led us to perform four pairwise comparisons (avir F versus vir Me3 or vir Me7; avir Mifield1 versus vir SM1; avirMifieldV versus vir SM2V). Bonferroni correction was consequently applied (significance level at $\varepsilon=0.05 / 4=0.0125$ instead of $\alpha=0.05$ ). Analyses were performed using the free software R (http://www.rproject.org/).

\section{Results}

All the $M$. incognita isolates tested were able to infest both the susceptible tomatoes and peppers, with IF ranging from 0.10 to 0.87 (Table 2). The avirulent isolates avir MifieldV and avir F produced fewer egg masses on the partially resistant pepper cv YW compared to the susceptible pepper DLL and tomato St Pierre or Marmande plants. As expected, i) avirulent isolates (avir MifieldV and avir F) were unable to reproduce on the resistant tomatoes or peppers (IF values ranging from 0 to 0.002 ); ii) selected isolates virulent on $\mathrm{Mi}-1$ tomato exhibited a high infestation frequency on this resistant tomato $(0.35 \leq \mathrm{IF} \leq 0.82)$; and iii) both selected and natural isolates virulent on $M e 3$ or Me7-pepper exhibited a high infestation frequency on the Me3-pepper $(0.23 \leq \mathrm{IF} \leq 0.81)$. Nevertheless, none of the virulent isolates (overcoming either tomato or pepper R genes) was able to reproduce on Me1-pepper, and both selected and natural isolates virulent on resistant peppers were unable to reproduce on Mi-1-tomato. One or two egg-masses were obtained on a few Me1-peppers, but these egg masses contained very few eggs (i.e., < 65 eggs; data not shown) compared to egg masses obtained on Me3-peppers (i.e., $>800$ eggs; data not shown) and they did not survive to a successive inoculation, so it was not possible to obtain a virulent isolate.

Considering the RP of the nematodes, we first observed that the RP of avirulent isolates was higher on susceptible tomato than on susceptible pepper (496.78 \pm 46.30 and $371.21 \pm 71.77$ for the avir $F$ on tomato and pepper, respectively; $238.78 \pm 35.13$ and $157.73 \pm 17.93$ for the avir MifieldV on tomato and pepper, respectively) (data not shown). When comparing the RP of a restricted set of the avirulent and virulent nematode populations on susceptible plants, we firstly evidenced significant differences between nematode populations $\left(\chi_{6 \mathrm{df}}{ }=40.8\right.$, $\mathrm{p}<10^{-3}$ ) (Figure 1). More interestingly, the hypothesis of a virulence cost was strongly supported in three of the four pairwise comparisons: avir F versus vir $M e 3\left(\mathrm{~W}=200 ; \mathrm{p}<10^{-3}\right)$; avir F versus vir Me7 ( $\mathrm{W}=279 ; \mathrm{p}<10^{-3}$ ); avir MifieldV versus vir SM2V (W=34; $\left.\mathrm{p}=0.004\right)$. In these three cases, the estimated fitness cost ranged from 54 to $71 \%$. In the last comparison (avir Mifield1 versus vir SM1), the same tendency was observed but the difference was not significant $(\mathrm{W}=23 ; \mathrm{p}=0.24)$; it is noteworthy that the sample size was nevertheless low.

Finally, when comparing the RP of virulent $M$. incognita isolates selected in the laboratory and in the field on both susceptible and resistant tomatoes and peppers (Figure 2), 
we observed high levels of variability between virulent lines on a same host, the number of eggs produced ranging from 106 to 496 times the number of J2s inoculated on susceptible cvs and from 0 to 435 times the number of $\mathrm{J} 2 \mathrm{~s}$ inoculated on resistant cvs. The $M e 3$ virulent isolates from Hungary (pop A, B and C) reproduced much more on all susceptible and Me3resistant pepper genotypes (RP ranging from 200 to 496) than the $M e 3$ virulent isolate issued from a single year of selection in greenhouse (vir CREAT) (RP ranging 117 from to 209), and than the laboratory selected isolates (vir Me3 and vir Me7) (RP ranging from 62 to 322).

\section{Discussion}

Selection for RKN resistance in crops, including tomato and pepper, is a major challenge for plant breeders. Therefore, because the introgression of R-genes into cvs of agronomic interest by successive back-crosses generally takes several years, a long-term goal of breeders is to select the genotypes (robust R-genes, their combination, and associated genetic backgrounds) that is expected to exhibit the best durability under field conditions (late emergence and low fitness of nematode virulent populations). In pepper, the Me1 R-gene appears to be a good candidate for such a purpose. Previous studies had shown that none of the $22 \mathrm{RKN}$ avirulent isolates tested, belonging to the three major species ( $M$. incognita, $M$. arenaria and $M$. javanica), were able to overcome this R-gene under laboratory artificial conditions (Castagnone-Sereno et al., 1996; 2001). In the present study, we further showed that neither natural nor selected virulent RKN isolates (overcoming either $\mathrm{Mi}-1$ from tomato or $M e 3$ or $M e 7$ from pepper) were able to reproduce on Me1-peppers. Such a result is in good agreement with previous data indicating that these R-genes are not equally overcome by RKNs, and that Me1 behaves as a robust R-gene. Conversely to $\mathrm{Mi}-1, \mathrm{Me} 3$ and $\mathrm{Me}$, Me1 induces a late hypersensitive reaction in the vascular cylinder of infested roots, thus inhibiting the development of egg-laying females (Bleve-Zacheo et al. 1998 ; Pegard et al. 2005). Our observations here support previous data suggesting that late expression of the hypersensitive reaction by $M e 1$ prevents (or at least strongly reduces) the frequency of emergence of virulent nematode genotypes. Additionally, this study demonstrates that both natural and selected RKN isolates virulent on resistant peppers are unable to reproduce on $\mathrm{Mi}-1$ tomato, and confirmed that selected isolates virulent on $\mathrm{Mi}-1$ tomato are unable to reproduce on $\mathrm{Me} 3$ and Me1 resistant peppers. The virulent isolate overcoming $M e 7$ was able to reproduce on Me3pepper, which may indicate that $M e 3$ and $M e 7$ maybe one single allele at the same gene. Indeed, two independent allelism tests performed with 385 test-cross lines [F1(CM334xHD149) x DLL] strongly suggested that $M e 3$ and $M e 7$ are allelic, since no susceptible plant was obtained on these 385 lines inoculated with 500 avirulent nematodes (Djian-Caporalino \& Castagnone-Sereno, unpublished). Moreover, the fact that RKN selected for virulence over $\mathrm{Me} 3$ also brokedown $\mathrm{Me} 7$ (and reciprocally) indicates these are a single allele. So, RKN isolates virulent on one resistant crop are definitively not virulent on a different resistant crop. These findings indicate that virulence is highly specific to the R-gene on which selection has occurred. As a result of such strict specificity of virulence, once virulent isolates are selected on a determined R-gene, it is very likely that alternance in the 
rotation with a different gene will improve soil health, except if multivirulence can be progressively selected, which remains to be demonstrated.

The reproduction potential of virulent laboratory-selected and wild $M$. incognita isolates exhibited high levels of variability on a same host, either susceptible or resistant. As nematode reproduction on resistant genotypes is generally explained by the interaction between the plant genotype and nematode isolate, but not by either factor alone (Ornat et al. 2001; Jacquet et al. 2005; Lopez-Perez et al. 2006; Cortada et al. 2008), we can hypothesize that the variability observed here in the infection and reproduction of virulent lines on a same host can be attributed to the nematode genetic background, because they did not originate from the same nematode population and they were not selected on the same resistant plants in laboratory and in fields, even if the R-gene in these plants was the same. The natural virulent isolates selected on resistant peppers seemed to reproduce better on susceptible and resistant Me3-peppers than laboratory-selected isolates. This observation may be correlated to the way these isolates acquired their virulence, and suggests that the genetic changes induced under managed pressure in artificial conditions are different from those occurring in natural $\mathrm{Me} 3$ resistance-breaking biotypes, as previously reported for laboratory-selected or natural isolates virulent againt the tomato Mi-1 R-gene (Castagnone-Sereno et al. 1994a; Roberts 1995). It may also result from the fact that laboratory-selected virulent isolates are very recent and have not yet been submitted to alternative hosts, conversely to natural virulent isolates that may be older and whose genetic background may have co-evolved with the virulence, thus restoring the nematode fitness.

Comparing the RP of the avirulent and laboratory-selected virulent nematodes revealed that both $\mathrm{Me} 3$ (or Me7) and $\mathrm{Mi}$-1-virulent isolates showed significant lower RPs on susceptible plants compared to the avirulent isolates, mainly due to a decrease in female fertility. This result indicates that some fitness cost reduced the nematode reproduction on the susceptible plants because of unnecessary virulence. This fitness cost may be associated to the virulence trait (pleiotropic effect) but may also result in part from the reduction of genetic variability operated by the selection pressure of the R-genes. Experimental evidence of such virulence fitness costs penalizing the aggressivity of virulent pathogens on susceptible plants has been abundantly reported for bacteria, fungi and viruses (e.g., Vera-Cruz et al. 2000; Jenner et al. 2002; Parlevliet 2002; Desbiez et al. 2003; Lecoq et al. 2004; Ayme et al. 2007; Sacristan and García-Arenal 2008; Janzac et al. 2009; 2010). However, similar data on RKNs remain scarce (Petrillo and Roberts 2005; Castagnone-Sereno et al. 2007). The present study reinforces these previous observations and suggests that such a fitness cost of virulent lines on susceptible crops is a general trend in plant pathogens, including nematodes. In our study, the virulence costs were estimated at 33 to $56 \%$ on susceptible tomatoes and at 54 to $71 \%$ on susceptible peppers. Thus, $\mathrm{Me} 3$ (or Me7) seemed to exert a higher selection pressure than $\mathrm{Mi}$ 1 on RKN populations, resulting in an increased fitness cost of virulence. Moreover, RP of avirulent isolates was higher on susceptible tomatoes than on susceptible peppers, suggesting that the so-called 'susceptible' peppers had some undetermined and partial resistance factors, able to confer a quantitative resistance to some virulent RKN isolates, that are not present in susceptible tomatoes. In that respect, it should be noted that resistance to some isolates of the closely related RKN species $M$. chitwoodi was previously observed in DLL (Berthou et al. 2003; Djian-Caporalino et al. 2007). Further investigations are currently underway in the 
laboratory to confirm this hypothesis, which may have major practical implications in terms of durability of the resistance (Palloix et al. 2009).

Host resistance is considered as an important component of integrated management of RKNs. Because few R-genes acting against these pests are currently available, it is urgently needed to protect them and promote their durability. Since resistance deployment is influenced by the variation in (a)virulence and host range, two primary attributes of host resistance for nematode resistance breeding and management are relevant: i) the value of resistance in crop self-protection, based on the level of resistance to injury caused by initial infection, and ii) the rotational value of resistance in cropping systems for protecting subsequent crops, based on the ability to decrease the nematode population densities in soil by restricting nematode reproduction (Roberts 1995). In pepper, the Me1 R-gene confers a high level of resistance without affecting the plant growth, is still active at high temperature, conversely to the tomato $\mathrm{Mi}-1$ resistance gene, is not overcome by both selected and natural virulent isolates overcoming $\mathrm{Mi}-1$ in tomato nor $\mathrm{Me} 3$ nor $\mathrm{Me} 7$ in pepper. This R-gene therefore looks suitable for either combination with $M e 3$ in pepper cvs ('pyramiding') or alternance with other R-genes ( $\mathrm{Me} 3$ or $\mathrm{Me}$, $\mathrm{Mi}-1)$ in crop rotations to strengthen and increase the durability of resistance. Experiments are now in progress to validate the obtained results under 3-year-field agronomic conditions comparing i) the alternance of single R-genes in rotation, ii) the mixture of genotypes bearing single R-genes sown in the same plot, and iii) the pyramiding of two R-genes in one genotype. Results will allow the identification of conditions lowering the emergence of virulent biotypes of RKN in the field, and the time required for the improvement of soil health (reduction of parasites under their damage threshold) using the R-plants as RKN 'traps'. This approach will help to promote the durability of those resistances against RKN, making breeders and farmers (resistance users) sensitive to the 'directions for use' necessary to keep their durability.

\section{Acknowledgements}

This research was carried out with the financial support from the European Commission (FP6-NoE ENDURE), and from the French Ministère de l'Agriculture de l'Alimentation et de la Pêche (MAAP, convention $\mathrm{N}^{\circ} \mathrm{C06/03)}$. 


\section{References}

Ayme, V., Petit-Pierre J., Souche, S., Palloix, A., \& Moury, B. (2007). Molecular dissection of the potato virus Y VPg virulence factor reveals complex adaptations to the pvr2 resistance allelic series in pepper. Journal of General Virology, 88, 1594-1601.

Berthou, F., Palloix, A., \& Mugniery, D. (2003). Characterisation of virulence in populations of Meloidogyne chitwoodi and evidence for a resistance gene in pepper Capsicum annuum L. line PM217. Nematology, 5, 383-390.

Bleve-Zacheo, T., Bongiovanni, M., Melillo, M.T., \& Castagnone-Sereno, P. (1998). The pepper resistance genes Me1 and Me 3 induce differential penetration rates and temporal sequences of root cell ultrastructural changes upon nematode infection. Plant Science, 133, 79-90.

Blok, V.C., Jones, J.T., Phillips, M.S., \& Trudgill, D.L. (2008). Parasitism genes and host range disparities in biotrophic nematodes: the conundrum of polyphagy versus specialisation. BioEssays, 30, 249-59.

Castagnone-Sereno, P. (2002). Genetic variability of nematodes: a threat to the durability of plant resistance genes? Euphytica 124, 193-199.

Castagnone-Sereno, P., Bongiovanni, M., \& Dalmasso, A. (1994a). Reproduction of virulent isolates of Meloidogyne incognita on susceptible and Mi-resistant tomato. Journal of Nematology, 26, 324-328.

Castagnone-Sereno, P., Bongiovanni, M., \& Djian-Caporalino, C. (2001). New data on the specificity of the root-knot nematode resistance genes Me1 and Me3 in pepper. Plant Breeding, 120, 429-433.

Castagnone-Sereno, P., Bongiovanni, M., Palloix, A., \& Dalmasso, A. (1996). Selection for Meloidogyne incognita virulence against resistance genes from tomato and pepper and specificity of the virulence/resistance determinants. European Journal of Plant Pathology, 102, 585-590.

Castagnone-Sereno, P., Bongiovanni, M., \& Wajnberg, E. (2007). Selection and parasite evolution: a reproductive fitness cost associated with virulence in the parthenogenetic nematode Meloidogyne incognita. Evolutionary Ecology, 21, 259-270.

Castagnone-Sereno, P., Wajnberg, E., Bongiovanni, M., Leroy, F., \& Dalmasso, A. (1994b). Genetic variation in Meloidogyne incognita virulence against the tomato Mi resistance gene: Evidence from isofemale line selection studies. Theoretical and Applied Genetics, 88, 749-753.

Cortada, L., Sorribas, F.J., Ornat, C., Kaloshian, I., \& Verdejo-Lucas, S. (2008). Variability in infection and reproduction of Meloidogyne javanica on tomato rootstocks with the Mi resistance gene. Plant Pathology, 57, 1125-1135.

Dalmasso, A., \& Bergé, J.B. (1978). Molecular polymorphism and phylogenetic relationship in some Meloidogyne spp.: Application to the taxonomy of Meloidogyne. Journal of Nematology, 10, 323-332.

Desbiez, C., Gal-On, A., Girard, M., Wipf-Scheibel, C., \& Lecoq, H. (2003). Increase in Zucchini yellow mosaic virus symptom severity in tolerant zucchini cultivars is related to a point mutation in $\mathrm{P} 3$ protein and is associated with a loss of relative fitness on susceptible plants. Phytopathology, 93, 1478-1484. 
Devran, Z., \& Sogut, M.A. (2010). Occurrence of virulent root-knot nematode isolates on tomatoes bearing the Mi gene in protected vegetable-growing areas of Turkey. Phytopathology, 38, 245-251.

Djian-Caporalino, C., Fazari, A., Arguel, M.J., Vernie, T., VandeCasteele, C., Faure, I., Brunoud, G., Pijarowski, L., Palloix, A., Lefebvre V., \& Abad, P. (2007). Root-knot nematode (Meloidogyne spp.) Me resistance genes in pepper (Capsicum annuum L.) are clustered on the P9 chromosome. Theoretical and Applied Genetics, 114, 473-486.

Djian-Caporalino, C., Pijarowski, L., Fazari, A., Samson, M., Gaveau, L., O’Byrne, C., V. Lefebvre, V., Caranta, C., Palloix, A., \& Abad, P. (2001). High-resolution genetic mapping of the pepper (Capsicum annuum L.) resistance loci Me3 and Me4 conferring heat-stable resistance to root-knot nematodes (Meloidogyne spp.). Theoretical and Applied Genetics, 103, 592-600.

Djian-Caporalino, C., Pijarowski, L., Januel, A., Lefebvre, V., Daubeze, A., Palloix, A., Dalmasso, A., \& Abad, P. (1999). Spectrum of resistance to root-knot nematodes and inheritance of heat-stable resistance in pepper (Capsicum annuum L.). Theoretical and Applied Genetics, 99, 496-502.

Hendy, H., Pochard, E., \& Dalmasso, A. (1985). Transmission héréditaire de la résistance aux nématodes Meloidogyne Chitwood (Tylenchida) portée par deux lignées de Capsicum annuum L.: étude de descendances homozygotes issues d'androgenèse. Agronomie, 5, 93-100.

Huang, X., McGiffen, M., \& Kaloshian, I. (2004). Reproduction of Mi-virulent Meloidogyne incognita isolates on Lycopersicon spp. Journal of Nematology, 36, 69-75.

Jacquet, M., Bongiovanni, M., Martinez, M., Verschave, P., Wajnberg, E., \& CastagnoneSereno, P. (2005). Variation in resistance to the root-knot nematode Meloidogyne incognita in tomato genotypes bearing the Mi gene. Plant Pathology, 54, 93-99.

Janzac, B., Fabre, F., Palloix, A., \& Moury, B. (2009). Constraints on evolution of virus avirulence factors predict the durability of corresponding plant resistances. Molecular Plant Pathology, 10, 599-610.

Janzac, B., Montarry, J., Palloix, A., Navaud, O., Moury, B. (2010). Point mutation in the polymerase of Potato virus Y confers virulence toward the Pvr4 resistance of pepper and a high competitiveness cost in susceptible cultivar. Molecular Plant-Microbe Interactions, 23, 823-830.

Jarquin-Barberena, H., Dalmasso, A., De Guiran, G., \& Cardin, M.C. (1991). Acquired virulence in the plant parasitic nematode Meloidogyne incognita. I. Biological analysis of the phenomenon. Revue de Nématologie, 14, 299-303.

Jenner, C.E., Wang, X., Ponz, F., \& Walsh, J.A. (2002). A fitness cost for Turnip mosaic virus to overcome host resistance. Virus Research, 86, 1-6.

Lecoq, H., Moury, B., Desbiez, C., Palloix, A., \& Pitrat, M. (2004). Durable virus resistance in plants through conventional approaches: a challenge. Virus Research, 100, 31-39.

Lopez-Perez, J.A., Le Strange, M., Kaloshian, I., \& Ploeg, A.T. (2006). Differential response of Mi gene-resistant tomato rootstocks to root-knot nematodes (Meloidogyne incognita). Crop Protection 25, 382-388.

Meher, H.C., Gajbhiye, V.T., Chawla, G., \& Singh, G. (2009). Virulence development and genetic polymorphism in Meloidogyne incognita (Kofoid \& White) Chitwood after 
prolonged exposure to sublethal concentrations of nematicides and continuous growing of resistant tomato cultivars. Pest Management Science, 65, 1201-1207.

Methyl Bromide Technical Options Committee (2006). Report of the Methyl Bromide Technical Options Committee. Non-chemical Alternatives Adopted as Replacements to Methyl Bromide on a Large Scale. Nairobi, Kenya: United Nation Environmental Programme, UNON Publishing Section Services, 39-73.

Ornat, C., Verdejo-Lucas, S., \& Sorribas, F.J. (2001). A population of Meloidogyne javanica in Spain virulent to the Mi resistance gene in tomato. Plant Disease 85, 271-276.

Palloix, A., Ayme V., \& Moury, B. (2009). Durability of plant major resistance genes to pathogens depends on the genetic background, experimental evidence and consequences for breeding strategies. New Phytologist, 183, 190-199.

Parlevliet, J.E. (2002). Durability of resistance against fungal, bacterial and viral pathogens; present situation. Euphytica, 124, 147-156.

Pegard, A., Brizzard, G., Fazari, A., Soucaze, O., Abad, P., \& Djian-Caporalino, C. (2005). Histological Characterization of Resistance to Different Root-knot Nematode species related to phenolics accumulation in Capsicum annuum L. Phytopathology, 95, 158165.

Petrillo, M.D., \& Roberts, P.A. (2005). Fitness of virulent Meloidogyne incognita isolates on susceptible and resistant cowpea. Journal of Nematology, 37, 457-466.

Roberts, P.A. (1995). Conceptual and practical aspects of variability in root-knot nematodes related to host plant resistance. Annual Review of Phytopathology, 33, 199-221.

Sacristán, S., \& García-Arenal, F. (2008). The evolution of virulence and pathogenicity in plant pathogen populations. Molecular Plant Pathology, 9, 369-384.

Sorribas, F.J., Ornat, C., Verdejo-Lucas, S., Galeano, M., \& Valero, J. (2005). Effectiveness and profitability of the Mi-resistant tomatoes to control root-knot nematodes. European Journal of Plant Pathology, 111, 29-38.

Tzortzakakis, E.A., Adam, M.A.M., Blok, V.C., Paraskevopoulos, C., \& Bourtzis, K. (2005). Occurrence of resistance-breaking isolates of root-knot nematodes on tomato in Greece. European Journal of Plant Pathology, 113, 101-105.

Tzortzakakis, E.A., da Conceicao, I.L.P.M., dos Santos, M.C.V., \& Abrantes, I.M. de O. (2008). Selection of virulent Meloidogyne individuals within mixed isolates by continuous cultivation on a Mi gene resistant tomato genotype. Journal of Plant Diseases and Protection, 115, 234-237.

Tzortzakakis, E.A., Trudgill, D.L., \& Phillips, M.S. (1998). Evidence for a dosage effect of the Mi gene on partially virulent isolates of Meloidogyne javanica. Journal of Nematology, 30, 76-80.

Vera Cruz, C.M, Bai, J., Oña, I., Leung, H., Nelson, R.J., Mew, T.W., and \& Leach J.E. (2000). Predicting durability of a disease resistance gene based on an assessment of the fitness loss and epidemiological consequences of avirulence gene mutation. Proceedings of the National Academy of Sciences of the USA, 97, 13500-13505.

Verdejo-Lucas, S., Cortada, L., Sorribas, F.J., \& Ornat, C. (2009). Selection of virulent isolates of Meloidogyne javanica by repeated cultivation of Mi resistance gene tomato rootstocks under field conditions. Plant Pathology, 58, 990-998. 
Williamson V.M., \& Roberts, P.A. (2009). Mechanisms and genetics of resistance. In: R.N. Perry, M. Moens and J.L. Starr, Editors, Root-knot Nematodes, CAB International, Wallingford, UK, 301-325.

Williamson, V.M., \& Kumar, A. (2006). Nematode resistance in plants: the battle underground. Trends in Genetics, 22, 396-403.

Zijlstra, C., Donkers-Venne, T.H.M., \& Fargette, M. (2000). Identification of Meloidogyne incognita, M. javanica and M. arenaria using sequence characterised amplified region (SCAR) based PCR assays. Nematology, 2, 847-853. 
Figure 1 Comparison of the reproduction potential (mean RP of 6 to 20 replicates \pm standard error) of avirulent and virulent laboratory-selected $M$. incognita isolates on tomato and pepper susceptible genotypes. NS = no significant difference; * = significant difference; $* *=$ highly significant difference.

\section{Figure 1}

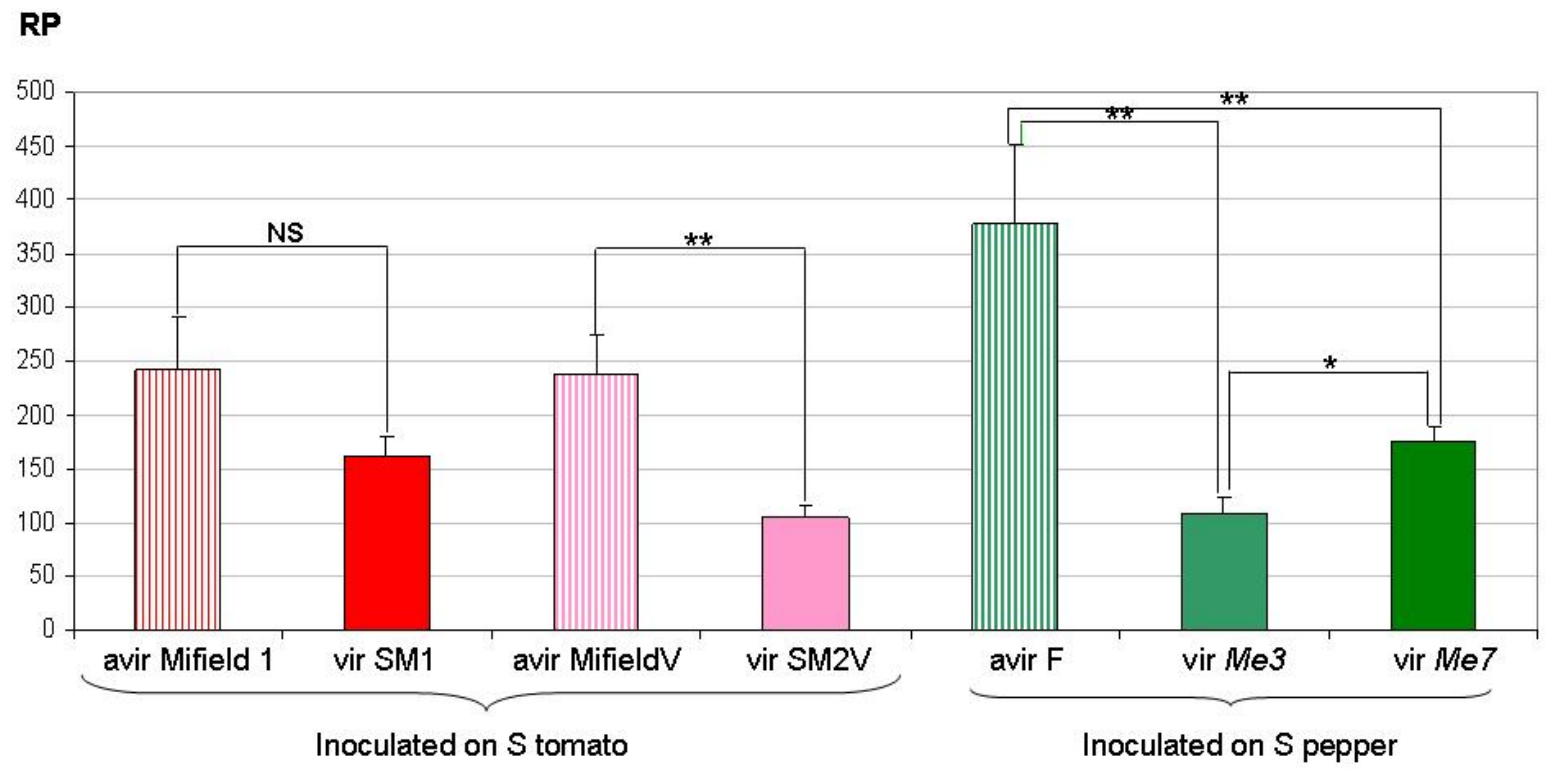


Figure 2 Comparison of the reproduction potential (mean RP of 6 to 20 replicates \pm standard error) of laboratory-selected and natural $M$. incognita virulent isolates on both susceptible and resistant tomatoes and peppers.

\section{Figure 2}

\section{$\mathbf{R P}$}

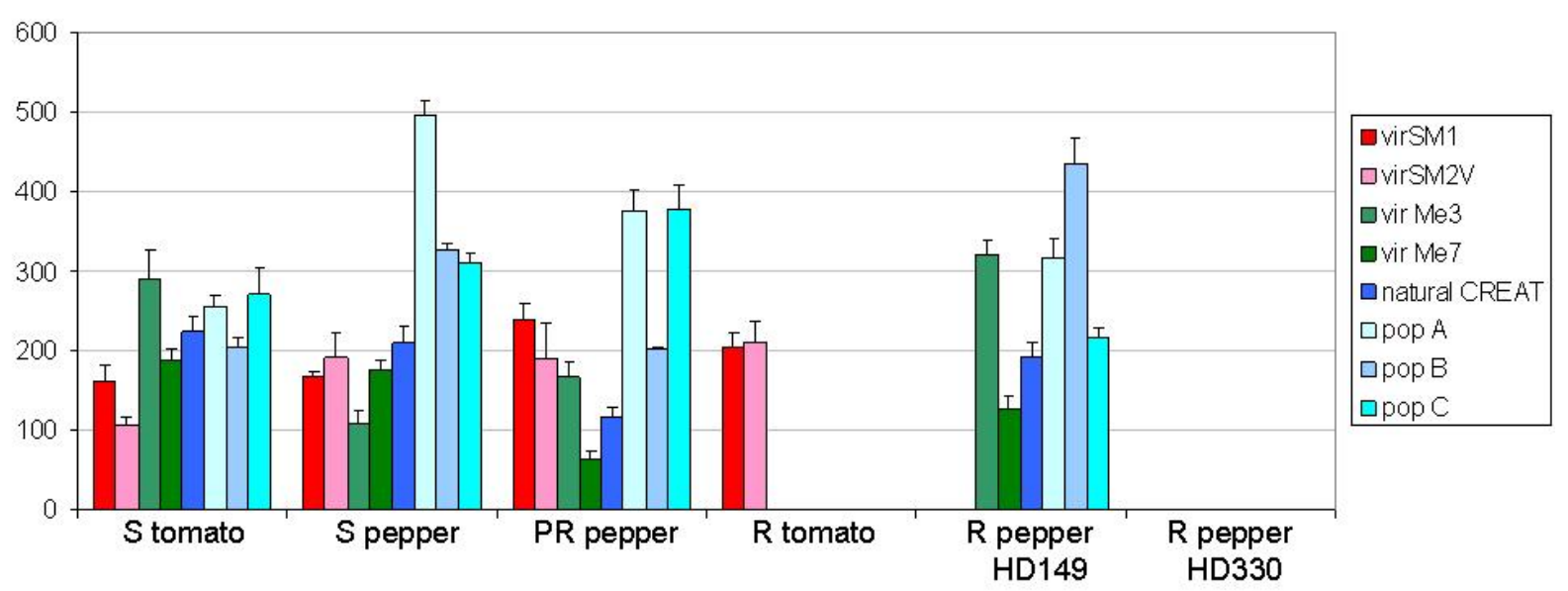


Table 1 Meloidogyne incognita isolates used in this study

\begin{tabular}{llll}
\hline Code & Geographic origin & Features & (a)virulence \\
\hline avir F & Morelos, Mexico & Reference isolate from the INRA collection & Avirulent \\
avir Mifield1 & Italy & Field isolate & Avirulent \\
avir MifieldV & Venezuela & Field isolate & Avirulent \\
vir $M i-1$ & France & Laboratory-selected on $M i$-1 from avir F & Virulent $M i-1$ \\
vir SM1 & Italy & Greenhouse-selected on $M i-1$ from avir Mifield1 & Virulent $M i-1$ \\
vir SM2V & Italy & Greenhouse-selected on $M i-1$ from avir MifieldV & Virulent $M i-1$ \\
vir Me3 & France & Laboratory-selected on $M e 3$ from avir F & Virulent $M e 3$ \\
vir CREAT & La Baronne, France & Field isolate naturally-selected on $M e 3$ & Virulent $M e 3$ \\
vir pop A & Hungary & Greenhouse-selected on $M e 3$ & Virulent $M e 3$ \\
vir pop B & Hungary & Greenhouse-selected on $M e 3$ & Virulent $M e 3$ \\
vir pop C & Hungary & Greenhouse-selected on $M e 3$ & Virulent $M e 3$ \\
vir $M e 7$ & France & Laboratory-selected on $M e 7$ from avir F & Virulent $M e 7$ \\
\hline
\end{tabular}




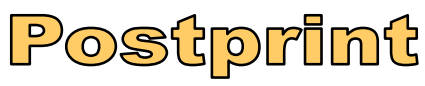

Version définitive du manuscrit publié dans / Final version of the manuscript published in : European Journal Plant Pathology, 2011, vol.131, pp 431-440, DOI: 10.1007/s10658-011-9820-4

Table 2 Infestation frequency (IF) of greenhouse and laboratory-selected Meloidogyne incognita isolates on susceptible vs. resistant tomato and pepper genotypes. Values are the mean ( \pm standard error) of 15 replicates.

\begin{tabular}{|c|c|c|c|c|c|c|c|c|c|c|c|c|}
\hline \multirow[t]{2}{*}{ Host genotypes ${ }^{\mathrm{a}}$} & \multicolumn{3}{|c|}{ Avirulent populations } & \multicolumn{3}{|c|}{$\begin{array}{l}\text { Laboratory selection on } \mathrm{Mi}-1 \\
\text { tomato }\end{array}$} & \multirow{2}{*}{$\begin{array}{l}\begin{array}{l}\text { Laboratory } \\
\text { selection on } \\
M e 3 \text { pepper }^{b}\end{array} \\
\text { vir Me3 }\end{array}$} & \multirow{2}{*}{ 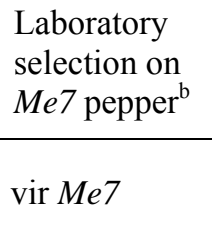 } & \multirow{2}{*}{$\begin{array}{l}\text { Greenhouse } \\
\text { selection on } \\
\text { Me3 pepper }\end{array}$} & \multicolumn{3}{|c|}{$\begin{array}{l}\text { Greenhouse selection on } \mathrm{Me} 3 \text { - } \\
\text { peppers }\end{array}$} \\
\hline & Avir F & $\begin{array}{l}\text { avir } \\
\text { Mifield1 }\end{array}$ & avir MifieldV & $\operatorname{vir} M i-l$ & Vir SMl & vir SM2V & & & & vir pop A & vir pop B & vir pop C \\
\hline S tomato & $0.41 \pm 0.03$ & $0.73 \pm 0.08$ & $0.49 \pm 0.06$ & $0.46 \pm 0.12$ & $0.35 \pm 0.03$ & $0.33 \pm 0.04$ & $0.31 \pm 0.03$ & $0.35 \pm 0.03$ & $0.32 \pm 0.02$ & $0.60 \pm 0.03$ & $0.42 \pm 0.03$ & $0.52 \pm 0.06$ \\
\hline $\mathrm{R}$ tomato $\mathrm{Mi}-1$ & $0.00 \pm 0.00$ & nd & $0.002 \pm 0.66$ & $0.82 \pm 0.14$ & $0.43 \pm 0.04$ & $0.35 \pm 0.06$ & $0.00 \pm 0.00$ & $0.00 \pm 0.00$ & $0.00 \pm 0.00$ & $0.00 \pm 0.00$ & $0.42 \pm 0.00$ & $0.00 \pm 0.00$ \\
\hline S pepper & $0.24 \pm 0.02$ & nd & $0.66 \pm 0.05$ & $\mathrm{Nd}$ & $0.44 \pm 0.02$ & $0.38 \pm 0.04$ & $0.17 \pm 0.01$ & $0.26 \pm 0.02$ & $0.27 \pm 0.02$ & $0.71 \pm 0.03$ & $0.87 \pm 0.03$ & $0.67 \pm 0.04$ \\
\hline PR pepper & $0.10 \pm 0.01$ & nd & $0.27 \pm 0.03$ & $0.00 \pm 0.00$ & $0.51 \pm 0.02$ & $0.41 \pm 0.05$ & $0.18 \pm 0.02$ & $0.12 \pm 0.02$ & $0.16 \pm 0.02$ & $0.71 \pm 0.03$ & $0.66 \pm 0.08$ & $0.43 \pm 0.03$ \\
\hline R pepper $M e 3$ & $0.002 \pm 0.001$ & nd & $0.00 \pm 0.00$ & $0.00 \pm 0.00$ & nd & $0.00 \pm 0.00$ & $0.38 \pm 0.02$ & $0.25 \pm 0.03$ & $0.23 \pm 0.02$ & $0.61 \pm 0.08$ & $0.81 \pm 0.06$ & $0.43 \pm 0.02$ \\
\hline $\mathrm{R}$ pepper $M e 1$ & $0.00 \pm 0.00$ & nd & $0.00 \pm 0.00$ & $0.0 \pm 0.00$ & nd & $0.00 \pm 0.00$ & $0.00 \pm 0.00$ & $0.00 \pm 0.00$ & $0.00 \pm 0.00$ & $0.00 \pm 0.00$ & $0.00 \pm 0.00$ & $0.00 \pm 0.00$ \\
\hline
\end{tabular}

${ }^{\mathrm{a}} \mathrm{S}=$ susceptible, $\mathrm{R}=$ resistant, $P R=$ partially resistant

${ }^{\mathrm{b}}$ The virulent isolates were selected from the avirulent ones by successive rearing on resistant tomatoes and peppers, respectively $n d=$ data not available 